\title{
Effect of calcium, bicarbonate, and albumin on capacitation-related events in equine sperm
}

\author{
B Macías-García ${ }^{1,2, *}$, L González-Fernández ${ }^{1,2, *}$, S C Loux² , A M Rocha ${ }^{1}$, T Guimarães ${ }^{1}$, \\ F J Peña ${ }^{4}$ D D Varner ${ }^{3}$ and K Hinrichs ${ }^{2,3}$ \\ ${ }^{1}$ CECA/ICETA - Animal Sciences Centre, ICBAS-University of Porto, Campus Agrario de Vairão, Rua Padre Armando \\ Quintas, 4485-661 Vairão, Portugal, Departments of ${ }^{2}$ Veterinary Physiology and Pharmacology and ${ }^{3}$ Large Animal \\ Clinical Sciences, College of Veterinary Medicine and Biomedical Science, Texas A\&M University, College Station, \\ Texas, USA and ${ }^{4}$ Laboratory of Equine Reproduction, Faculty of Veterinary Medicine, Veterinary Teaching Hospital, \\ University of Extremadura, Cáceres, Spain
}

Correspondence should be addressed to B Macías-García; Email: bea_macias@hotmail.com

*(B Macías-García and L González-Fernández contributed equally to this work)

\begin{abstract}
Repeatable methods for IVF have not been established in the horse, reflecting the failure of standard capacitating media to induce changes required for fertilization capacity in equine sperm. One important step in capacitation is membrane cholesterol efflux, which in other species is triggered by cholesterol oxidation and is typically enhanced using albumin as a sterol acceptor. We incubated equine sperm in the presence of calcium, BSA, and bicarbonate, alone or in combination. Bicarbonate induced an increase in reactive oxygen species (ROS) that was abolished by the addition of calcium or BSA. Bicarbonate induced protein tyrosine phosphorylation (PY), even in the presence of calcium or BSA. Incubation at high pH enhanced PY but did not increase ROS production. Notably, no combination of these factors was associated with significant cholesterol efflux, as assessed by fluorescent quantitative cholesterol assay and confirmed by filipin staining. By contrast, sperm treated with methyl- $\beta$-cyclodextrin showed a significant reduction in cholesterol levels, but no significant increase in PY or ROS. Presence of BSA increased sperm binding to bovine zonae pellucidae in all three stallions. These results show that presence of serum albumin is not associated with a reduction in membrane cholesterol levels in equine sperm, highlighting the failure of equine sperm to exhibit core capacitation-related changes in a standard capacitating medium. These data indicate an atypical relationship among cholesterol efflux, ROS production, and PY in equine sperm. Our findings may help to elucidate factors affecting failure of equine IVF under standard conditions.
\end{abstract}

Reproduction (2015) 149 87-99

\section{Introduction}

Mammalian spermatozoa remain incapable of fertilization until they undergo a maturational process in the female reproductive tract known as capacitation (Austin 1951, Chang 1951). Capacitation encompasses a number of intricately related and poorly understood events, including an increase in intracellular bicarbonate and calcium levels, in association with plasma membrane reorganization as a result of cholesterol depletion (Flesch \& Gadella 2000, Gadella \& Van Gestel 2004). These initial events are associated with a complex intracellular cascade modulated via the adenylyl cyclase-CAMP-protein kinase A (PKA) pathway, whose final hallmark is an overall increase in phosphorylation of tyrosine residues (PY) of a large number of proteins (Visconti et al. 1999a). Loss of membrane cholesterol is a vital part of this pathway; Visconti et al. (1999b) demonstrated that suppression of cholesterol efflux inhibited the increase in PY in mouse sperm, although this could be bypassed by direct activation of the cAMP pathway (Visconti et al. 1999b, Wertheimer et al. 2008). Once capacitated, sperm become capable of undergoing subsequent fertilization-related processes when exposed to the appropriate stimuli, including zona pellucida (ZP) binding, the acrosome reaction, oocyte penetration, and, finally, fusion with the female gamete (Visconti et al. 1998, 2011).

Capacitation can be achieved in vitro in most species by incubation of sperm in a medium that imitates the environment of the female reproductive tract (Yanagimachi 1994, Freeman \& England 2013), typically the one containing BSA, calcium, and bicarbonate (standard capacitating medium). Addition of BSA, a cholesterol acceptor, is associated with cholesterol efflux from the sperm plasma membrane in boar, human, and 
mice (Boerke et al. 2008, Tulsiani \& Abou-Haila 2011). Cholesterol efflux not only supports PY but also allows phospholipid scrambling that will in turn yield plasma membrane lipid microdomain reorganization promoting sperm-ZP binding and the acrosome reaction (Boerke et al. 2008). Cholesterol efflux in sperm has been shown to be dependent upon active externalization of the sterol to make it available to sterol acceptors in the medium; this takes place through members of the ATP-binding cassette $(A B C)$ transporter superfamily in mice (Morales et al. 2012). ABCA1, ABCA7, ABCA17, and ABCG1 have been detected in mouse sperm (Morales et al. 2008) and ABCA1 has also been identified in dog sperm (Palme et al. 2014). Inhibition of ABCA1, ABCA7, and ABCG1 in mouse sperm in turn inhibits IVF, confirming that cholesterol efflux plays a core role in the physiology of capacitation and gamete interaction.

During capacitation, a mild increase in reactive oxygen species (ROS) production occurs in mammalian spermatozoa (O'Flaherty et al. 2006). Different oxygen radicals such as superoxide anion, nitric oxide, and hydrogen peroxide have been related to sperm capacitation (Griveau et al. 1994, de Lamirande et al. 2009, Rodriguez et al. 2011) and the addition of ROS yields an increase in PY in a variety of species (Baumber et al. 2003, Roy \& Atreja 2008, Kota et al. 2010, Dona et al. 2011). It has recently been shown that ROS generation during capacitation may be necessary for cholesterol efflux from the sperm plasma membrane. ROS oxidizes cholesterol to form oxysterols; this appears to be associated with depletion of both oxysterols and unoxidized cholesterol from the plasma membrane (Brouwers et al. 2011, Boerke et al. 2013). It is postulated that formation of oxysterols may activate the sterol transporter proteins, which make sterols available to cholesterol acceptors such as albumin (Boerke et al. 2013).

Non-physiological cholesterol acceptors such as cyclodextrins (cyclic oligosaccharides consisting of $7 \alpha$ (1-4)-glucopyranose units) have been shown to also alter the cholesterol content of sperm cell membranes (Ohtani et al. 1989, Choi \& Toyoda 1998, Flesch et al. 2001) and induce an increase in PY (Osheroff et al. 1999, Visconti et al. 1999c). Interestingly, the cholesterol complexing agent, methyl- $\beta$-cyclodextrin $(M \beta C D)$, does not require cholesterol oxidation in order to effectively remove cholesterol from the sperm plasma membrane (Boerke et al. 2013).

No repeatable method for efficient equine IVF has yet been established, indicating a failure to effectively capacitate equine spermatozoa. In the absence of fertilization, induction of PY has been used as a marker for capacitation-related changes in equine sperm. McPartlin et al. (2008) reported that incubation of equine sperm at a concentration of $10 \times 10^{6} / \mathrm{ml}$ in air in a modified Whitten's (MW) medium, supplemented with bicarbonate, calcium, and BSA, was associated with increased PY. We have recently demonstrated that it is the increase in environmental $\mathrm{pH}$ associated with incubation of this bicarbonate-containing medium in air, in the presence of a low sperm concentration, that is the core mediator of $\mathrm{PY}$ in this treatment, as high environmental $\mathrm{pH}(\sim 7.9$, the $\mathrm{pH}$ found in the mare's uterus post-inseminaton; Gonzalez-Fernandez et al. 2012) was associated with increased PY even in the absence of added bicarbonate or BSA. Notably, in equine sperm incubated at standard $\mathrm{pH}(\leq 7.4)$, both calcium and BSA exerted an inhibitory effect on PY (Gonzalez-Fernandez et al. 2012, 2013). These findings are in contrast to those described in murine sperm in which BSA or other cholesterol acceptors promote PY in the standard medium (Visconti et al. 1999b).

BSA is typically added to media during attempts at equine sperm capacitation, with the assumption that it serves to remove cholesterol from the equine sperm plasma membrane (Baumber et al. 2003, Pommer et al. 2003, Thomas et al. 2006, McPartlin et al. 2008, 2009). However, little work has been done to examine the relationship of serum albumin or other cholesterol acceptors with membrane cholesterol efflux, ROS production, or induction of $\mathrm{PY}$ in equine sperm. An increase in PYassociated with treatment with $M \beta C D$ was reported in equine sperm, but this was examined only in media containing activators of the CAMP-PKA pathway (Pommer et al. 2003); such activators essentially bypass the dependence of PY on cholesterol efflux (Visconti et al. 1995). Similarly, Bromfield et al. (2014) have recently evaluated factors affecting cholesterol reorganization patterns and PY in equine sperm, but essentially only in the presence of pentoxifylline and dibutyryl cAMP. Incubation of equine sperm with $M \beta C D$ in the basal medium (not containing stimulators of the CAMPPKA pathway) promoted changes in measures of membrane fluidity and cholesterol organization, but did not significantly increase PY; remarkably, the effects of BSA on these parameters in the basal medium were not reported (Bromfield et al. 2014).

The inhibitory effect of BSA on PY in equine sperm under standard incubation conditions (GonzalezFernandez et al. 2012) suggests that albumin is not acting as a cholesterol acceptor under these conditions. The aim of this study was to test the influence of factors utilized in the standard capacitating medium (BSA, calcium, and bicarbonate), and the effects of environmental $\mathrm{pH}$, on the capacitation-related events of ROS production, cholesterol efflux, PY, and binding of capacitated equine sperm to the ZP. The latter was tested in a heterologous (bovine) system, as validated previously (Coutinho da Silva et al. 2012), due to scarcity of equine oocytes. These findings may help to determine, in equine sperm, factors influencing the physiological changes canonically associated with capacitation, thus helping to illuminate mechanisms underlying the failure of equine IVF and adding to our understanding of comparative sperm biology. 


\section{Materials and methods}

\section{Chemicals and reagents}

All reagents were purchased from Sigma-Aldrich, Inc. unless otherwise stated.

\section{Media}

The basal medium used was that utilized by McPartlin et al. (2008), i.e., $\mathrm{MW}$ medium, consisting of $100 \mathrm{mM} \mathrm{NaCl}, 4.7 \mathrm{mM}$ $\mathrm{KCl}, 1.2 \mathrm{mM} \mathrm{MgCl}$, $5.5 \mathrm{mM}$ glucose (anhydrous), $22 \mathrm{mM}$ HEPES, $2.4 \mathrm{mM}$ sodium lactate, and $1.0 \mathrm{mM}$ pyruvic acid. The medium with bicarbonate was prepared by adding $25 \mathrm{mM}$ $\mathrm{NaHCO}_{3}$ (MW+Bic). For some media, $2.4 \mathrm{mM} \mathrm{CaCl}{ }_{2}$ was added (MW+Bic + Ca). Media containing calcium, bicarbonate, and BSA $(7 \mathrm{mg} / \mathrm{ml})$ were designated $\mathrm{MW}+++$. All media were adjusted by varying $(\mathrm{NaCl})$ to achieve an osmolality of 290-300 mOsm/kg; initial $\mathrm{pH}$ was adjusted to 7.25, 7.9, or 8.5, depending upon treatment, using $1 \mathrm{M} \mathrm{NaOH}$. When used, bicarbonate was added $1 \mathrm{~h}$ before the experiment and all media were maintained at $37^{\circ} \mathrm{C}$ in air until the beginning of the experiment, at which time the $\mathrm{pH}$ was determined again and adjusted to the desired value, if necessary.

\section{Semen collection and processing}

Semen was collected from seven mature light-breed stallions, using an artificial vagina (Missouri Model AV, Nasco, Ft. Atkinson, WI, USA). A nylon in-line filter (Animal Reproduction Systems, Chino, CA, USA) was used to eliminate the gel fraction. All experimental procedures were performed according to the United States Government Principles for the Utilization and Care of Vertebrate Animals Used in Testing, Research and Training. Procedures performed in Texas were approved by the Institutional Animal Care and Use Committee at Texas A\&M University. The stallions used at the University of Porto were maintained according to institutional and European regulations; the ejaculates used were aliquots of commercial doses used in the reproductive clinic of the Center of Animal Reproduction of Vairão (University of Porto) with the owner's consent. Each experiment utilized a minimum of one ejaculate from each of three different stallions.

Sperm were processed as described previously (GonzalezFernandez et al. 2013). Briefly, the sperm-rich fraction was diluted 1:5 (v:v) in the MW medium in a $15-\mathrm{ml}$ conical tube. The sperm suspension was centrifuged at $400 \mathrm{~g}$ for $10 \mathrm{~min}$ at room temperature $\left(22-24{ }^{\circ} \mathrm{C} ; \mathrm{RT}\right)$, then the supernatant was discarded, and the pellet was resuspended in $10 \mathrm{ml}$ of $\mathrm{MW}$ and centrifuged again at $400 \mathrm{~g}$ for $10 \mathrm{~min}$ at RT. The sperm concentration in the resulting pellet was then determined using a NucleoCounter SP-100 (Chemometec, Allerød, Denmark) and the suspension adjusted to a final concentration of $10 \times 10^{6} \mathrm{sperm} / \mathrm{ml}$. If addition of $M \beta C D$ was performed, the medium was supplemented with the designated treatment before final sperm dilution. Aliquots of the final sperm suspension $(500 \mu \mathrm{l})$ were placed in 5 -ml round-bottom plastic tubes (BD Falcon; San Jose, CA, USA). The tubes were incubated at $37^{\circ} \mathrm{C}$ in air for $4 \mathrm{~h}$.

\section{Cholesterol quantification}

Sperm were incubated in basal MW (initial pH 7.25) containing different concentrations of $\operatorname{M\beta CD}(0.1,1$, and $3 \mathrm{mM}$ ) or in MW supplemented with $25 \mathrm{mM}$ bicarbonate, $7 \mathrm{mg} / \mathrm{ml} \mathrm{BSA}$ (Sigma A7030), and $2.4 \mathrm{mM} \mathrm{CaCl}_{2}(\mathrm{MW}+++$ ). Incubation was performed at a concentration of $10 \times 10^{6}$ sperm $/ \mathrm{ml}$, at $37^{\circ} \mathrm{C}$ in air for $4 \mathrm{~h}$ in a final volume of $500 \mu \mathrm{l}$. For this experiment, sperm from four different stallions were used $(n=4$ ejaculates total).

Sperm cholesterol levels were quantified using Amplex Red cholesterol assay kit according to the manufacturer's instructions (Molecular Probes, Eugene, OR, USA). All samples were incubated in duplicate. Sperm cholesterol extraction was performed using a modification of a protocol described previously (Nicholson \& Ferreira 2009). Briefly, after incubation, the samples were transferred to $1.5 \mathrm{ml}$ Eppendorf tubes and centrifuged at $5000 \mathrm{~g}$ for $4 \mathrm{~min}$ at room temperature (RT). After centrifugation, the supernatant was removed and the samples were washed with $1 \mathrm{ml}$ of PBS. The samples were centrifuged again (5000 $\mathrm{g}$, $4 \mathrm{~min}$ at RT), the supernatant was removed, and $25 \mu \mathrm{l}$ of the Amplex Red reaction buffer $1 \times(\mathrm{RB}$ $1 \times$ ) were added to the samples. The samples were thoroughly pipetted to disaggregate the pellet and were placed at $4{ }^{\circ} \mathrm{C}$ for $10 \mathrm{~min}$ to allow for protein and cholesterol extraction. After this procedure, the samples were centrifuged for $10 \mathrm{~min}$ at $16000 \mathrm{~g}$ at $4{ }^{\circ} \mathrm{C}$. The supernatants containing the sperm extracts were transferred to $100-\mu \mathrm{l}$ Eppendorf tubes and immediately used for protein quantification, using the BioRad DC Protein Assay according to the manufacturer's instructions.

For cholesterol assay, $15 \mu \mathrm{l}$ of the sperm extracts of each sample were placed in a 96-well plate and $35 \mu$ of RB $1 \times$ were added to each well to reach a final sample volume of $50 \mu \mathrm{l}$. After this, an equivalent volume of Amplex Red working solution $(300 \mu \mathrm{M}$ Amplex Red, $2 \mathrm{U} / \mathrm{ml}$ cholesterol oxidase, $2 \mathrm{U} / \mathrm{ml}$ cholesterol esterase, and $2 \mathrm{U} / \mathrm{ml} \mathrm{HRP}$ ) was added. The samples were incubated at $37^{\circ} \mathrm{C}$ in the dark for $30 \mathrm{~min}$ and fluorescence (565 nm excitation; $585 \mathrm{~nm}$ emission) was measured using a 96-well plate in a Synergy MX microplate reader (Bio-Tek, Winooski, VT, USA). Cholesterol values were calculated using the cholesterol standard provided in the kit and normalized to the protein content.

\section{Filipin assay}

Equine sperm were prepared and incubated as described previously, at an initial pH of 7.25. The experiment was carried out using one ejaculate from each of three different stallions. One hundred sperm were evaluated per ejaculate.

Plasma membrane distribution of cholesterol was determined using filipin, a fluorescent polyene macrolide antibiotic that binds specifically to cholesterol (Flesch et al. 2001). The protocol used is a modification of the one described by Shadan et al. (2004). After incubation, samples were transferred to $1.5-\mathrm{ml}$ Eppendorf tubes and were centrifuged at $5000 \mathrm{~g}$ for $4 \mathrm{~min}$ at room temperature. The supernatant was removed, $490 \mu$ l of PBS were added to each tube, and the pellet was carefully resuspended. A stock solution of $10 \mathrm{mg} / \mathrm{ml}$ of 
filipin was prepared in $100 \%$ ethanol; $10 \mu \mathrm{l}$ of this solution were added to $490 \mu \mathrm{l}$ of the sperm solution $\left(10 \times 10^{6} \mathrm{sperm} / \mathrm{ml}\right)$ yielding a final concentration of $200 \mu \mathrm{g} / \mathrm{ml}$ of filipin and $2 \%$ ethanol. The samples were incubated in the dark at RT for $30 \mathrm{~min}$, washed twice by centrifugation $(5000 \mathrm{~g}$ for $4 \mathrm{~min}$ at $\mathrm{RT}$ ) in $1 \mathrm{ml}$ of PBS, and the pellet was resuspended in $40 \mu \mathrm{l}$ of PBS. Twenty microliters of this suspension were smeared on a slide and were mounted using ProLong Antifade (Life Technologies Corporation) according to the manufacturer's instructions. The samples were stored in the dark overnight, sealed using nail polish, and visualized the following day under a fluorescence microscope (excitation $365 \mathrm{~nm}$, emission $>420 \mathrm{~nm}$ ). Samples were evaluated using an Olympus BX60 fluorescence microscope (New Hyde Park, NY, USA) equipped with a $20 \times$ objective. At least 100 sperm per sample were evaluated visually.

\section{Effect of medium components on sperm cholesterol content}

Sperm were incubated in basal MW (initial pH 7.25) or in MW supplemented with $25 \mathrm{mM}$ bicarbonate (MW+Bic), $2.4 \mathrm{mM}$ $\mathrm{CaCl}_{2}(\mathrm{MW}+\mathrm{Ca})$, or $7 \mathrm{mg} / \mathrm{ml}$ BSA A7030 (MW+BSA), alone or in combination. In addition, $\mathrm{MW}+++$ was tested at initial $\mathrm{pH} 7.9$ and $\mathrm{pH}$ 8.5. The incubation was performed at a concentration of $10 \times 10^{6} \mathrm{sperm} / \mathrm{ml}$, at $37^{\circ} \mathrm{C}$ in air for $4 \mathrm{~h}$ in a final volume of $500 \mu \mathrm{l}$ (one ejaculate from each of four stallions; $n=4)$. Cholesterol quantification was performed as described earlier.

\section{Effect of albumin type and concentration on sperm cholesterol content}

To evaluate whether the unexpected lack of cholesterol efflux after incubation with BSA in the previous experiment was due to albumin type or concentration, sperm cholesterol content was evaluated after processing sperm as above, but incubating in MW containing 0,7 , or $20 \mathrm{mg} / \mathrm{ml}$ of five types of albumin: BSA 7030 (Sigma; heat-shock fractionated, fatty-acid free), BSA 9418 (Sigma; ethanol fractionated, fatty-acid free), equine serum albumin (eSA, Rocky Mountain Biologicals, Missoula, MT, USA), equine SA treated to remove lipid (LD-eSA) (via methanol and chloroform treatment, as described by Wessel \& Flugge (1984)) and human serum albumin (hSA; Sigma A1887; heat-fractionated, fatty-acid free). Based on the results of the previous experiment, $3 \mathrm{mM} M \beta C D$ was used as a positive cholesterol efflux control. One ejaculate from each of three different stallions was evaluated.

Owing to the large amount of albumin added in this study, the final sperm number, rather than protein concentration, was used to determine the cholesterol content. To do this, after removal of the final supernatant for cholesterol assay, the pellet was resuspended in $500 \mu \mathrm{l} \mathrm{PBS}$. The concentration of sperm in this suspension was determined using NucleoCounter as described earlier. The results of the cholesterol assay were then expressed in ng of cholesterol/million sperm.

To determine the cholesterol content of the albumin preparations themselves, MW was prepared containing 0, 7, or $20 \mathrm{mg} / \mathrm{ml}$ of the respective albumin preparations; then, the cholesterol assay was performed as outlined above but using $5 \mu \mathrm{l}$ of the medium, rather than sperm suspension, added to $25 \mu \mathrm{l} X 1$ in the initial step.

\section{Evaluation of ROS production}

Sperm were incubated in basal MW (initial $\mathrm{pH}$ 7.25) or in $\mathrm{MW}$ supplemented with $25 \mathrm{mM}$ bicarbonate (MW+Bic), $2.4 \mathrm{mM}$ $\mathrm{CaCl}_{2}(\mathrm{MW}+\mathrm{Ca})$, or $7 \mathrm{mg} / \mathrm{ml}$ BSA A7030 (MW+BSA), alone or in combination. In addition, $\mathrm{MW}+++$ was tested at initial $\mathrm{pH} 7.9$ and $\mathrm{pH} 8.5$, and $\mathrm{MW}$ was tested with $0.1,1$, and $3 \mathrm{mM}$ $M \beta C D$. The incubation was performed at a concentration of $10 \times 10^{6} \mathrm{sperm} / \mathrm{ml}$, at $37^{\circ} \mathrm{C}$ in air for $4 \mathrm{~h}$ in a final volume of $500 \mu \mathrm{l}$ (three ejaculates from three stallions; $n=3$ ).

The protocol used was a modification of that designed by Minervini et al. (2010). Briefly, after the incubation, $100 \mu \mathrm{l}$ of each sample were resuspended in $900 \mu$ of prewarmed PBS and $2^{\prime}, 7^{\prime}$-dichlorofluorescein diacetate (DCFDA) was added to reach a final concentration of $5 \mu \mathrm{M}$. This suspension was incubated at $37^{\circ} \mathrm{C}$ for $30 \mathrm{~min}$ in the dark; in the last $5 \mathrm{~min}, 1 \mu \mathrm{l}$ of propidium iodide $(\mathrm{PI})$ was added (final concentration, $1 \mu \mathrm{M}$ ). DCFDA is a cell-permeable non-fluorescent probe that becomes de-esterified intracellularly and turns to highly fluorescent $2^{\prime}, 7^{\prime}$-dichlorofluorescein upon oxidation by ROS, emitting at a wavelength of $530 \mathrm{~nm}$ (detected by FL1); cell viability was simultaneously assessed by detection of fluorescence of the non-permeant probe $\mathrm{PI}$, emitting at a wavelength of $617 \mathrm{~nm}$ (detected by FL3). After the dye-sperm co-incubation, 10000 sperm were evaluated using a Beckman Coulter EPICS XL flow cytometer (Coulter Corporation, Inc., Miami, FL, USA) equipped with standard optics, an argon-ion laser (Cyonics, Coherent, Santa Clara, CA, USA) performing $15 \mathrm{~mW}$ at a wavelength of $488 \mathrm{~nm}$ and the EXPO 2000 software. For each experiment, the non-stained cells were delimited in the quartile denominated as B3 as shown in Supplementary Figure 2, see section on supplementary data given at the end of this article; this region was delimited using a non-stained control. Cells were considered positively stained when PI or DCFDA fluorescence was detected above this threshold. In our study, only live sperm producing ROS were considered (B4 quadrant of Supplementary Figure 2). Representative scatterplots are shown in Supplementary Figure 2.

\section{Immunocytochemistry for PY}

Sperm were incubated under the same conditions as for the previous experiment. Two ejaculates from each of three stallions were evaluated. Following incubation, sperm were centrifuged for $3 \mathrm{~min}$ at $5000 \mathrm{~g}$ and washed with $1 \mathrm{ml}$ of PBS. After centrifugation, the pellet was resuspended in $1 \mathrm{ml}$ of PBS and the cell concentration was adjusted to $5 \times 10^{6}$ spermato$\mathrm{zoa} / \mathrm{ml}$. Ten microliters of the sample were placed on a slide pretreated with poly-L-lysine. After $10 \mathrm{~min}$, spermatozoa were fixed with 4\% formaldehyde in PBS for $15 \mathrm{~min}$ at room temperature and permeabilized with $0.1 \%$ Triton X-100 (v:v) in PBS for $10 \mathrm{~min}$. After three washes with PBS, sperm were blocked with $3 \%$ BSA in PBS for $60 \mathrm{~min}$. Primary incubation with antiphosphotyrosine MAB (4G10) (diluted 1:500) was 
performed in $3 \%$ BSA in PBS at $4{ }^{\circ} \mathrm{C}$ overnight. The sample was then washed with PBS and incubated with an anti-mouse IgG (FITC)-conjugated secondary antibody in 3\% BSA in PBS for $1 \mathrm{~h}$ at RT. After three washings with PBS, the samples were mounted on a slide with Slowfade gold antifade solution (Molecular Probes) according to the manufacturer's instructions. Samples were evaluated using a CyScope Plus HP-Partec fluorescence microscope (Swedesboro, NY, USA) equipped with a $100 \times$ objective. One hundred sperm per sample were examined, and the number of stained tails was counted.

\section{In vitro maturation and preparation of bovine oocytes}

Bovine ovaries were collected at a nearby abattoir and were maintained at $30{ }^{\circ} \mathrm{C}$ in saline solution $(0.9 \% \mathrm{NaCl})$ during transport ( $2 \mathrm{~h}$ total). After arrival at the laboratory, the ovaries were thoroughly rinsed with PBS at $37^{\circ} \mathrm{C}$ and the oocytes were aspirated from $2-8-\mathrm{mm}$ follicles using a $10 \mathrm{ml}$ plastic syringe attached to a 20-ga hypodermic needle. Oocytes with three or more layers of compact cumulus cells were cultured in tissue culture medium 199 (TCM-199) with Earle's salts and 25 mM HEPES supplemented with $10 \%$ fetal bovine serum (FBS; Thermo Scientific HyClone, Logan, UT, USA), $10 \mathrm{mU} / \mathrm{ml}$ of follicle-stimulating hormone (FSH; Life Technologies Corporation), $10 \mathrm{mU} / \mathrm{ml}$ of luteinizing hormone ( $\mathrm{LH}$; Life Technologies Corporation), and penicillin-streptomycin $(10 \mathrm{U} / \mathrm{ml}$ of penicillin and $10 \mu \mathrm{g} / \mathrm{ml}$ of streptomycin). Five hundred microliters of this media were placed in four well Nunc chambers, covered with cell culture mineral oil $(500 \mu \mathrm{l})$ and allowed to equilibrate for at least $3 \mathrm{~h}$ before placement of oocytes in a $5 \% \mathrm{CO}_{2} / 95 \%$ air incubator with $100 \%$ humidity set at $39^{\circ} \mathrm{C}$. Up to 50 oocytes were placed in each well and incubated for $24 \mathrm{~h}$.

After maturation, cumulus cells surrounding the oocytes were removed by vortexing the complexes in a $15-\mathrm{ml}$ conical tube for $3 \mathrm{~min}$ in $4 \mathrm{ml}$ of PBS supplemented with $0.4 \%$ hyaluronidase and $0.2 \%$ polyvinylalcohol (PVA). After vortexing, the oocytes were transferred to TCM-199 supplemented with $10 \%$ FBS. The oocytes were divided randomly into groups of five to seven oocytes and were washed three times in their respective medium before placement in the binding droplets, as described below.

\section{Heterologous binding assay}

The protocol used was a modification of that reported previously (Choi et al. 2003). Briefly, sperm were incubated at initial $\mathrm{pH} 7.25$ in $\mathrm{MW}, \mathrm{MW}+\mathrm{Bic}+\mathrm{Ca}, \mathrm{MW}+++$, or $\mathrm{MW}+++$ with $0.1 \mathrm{mM}$ or $1 \mathrm{mMM} \beta \mathrm{CD}$. To examine whether the effect of BSA might be modulated by $\mathrm{pH}$, sperm were also incubated in $\mathrm{MW}+++$ at initial $\mathrm{pH}$ 7.9. Treatment with $3 \mathrm{mMM} \beta C D$ and media devoid of calcium, as used in previous studies, were not evaluated (with the exception of basal MW as a control), because subjective sperm motility decreased dramatically in these treatments (data not shown). This experiment was performed using a minimum of four ejaculates from each of three different stallions: stallion IP, stallion JC, and stallion XA. Spermatozoa were incubated at $37^{\circ} \mathrm{C}$ in air for $4 \mathrm{~h}$ at a concentration of $10 \times 10^{6} \mathrm{sperm} / \mathrm{ml}$ in $500 \mu \mathrm{l}$ medium, as described earlier.

For sperm-oocyte co-incubation, the cumulus-denuded bovine oocytes were placed in $90-\mu$ d droplets of the medium under oil before addition of sperm. The droplets were prepared with $\mathrm{MW}, \mathrm{MW}+\mathrm{Bic}+\mathrm{Ca}$, or $\mathrm{MW}+++$ at $\mathrm{pH} 7.25$ or with $\mathrm{MW}+++$ at $\mathrm{pH} 7.9$, for sperm capacitated in the homologous treatments. Sperm capacitated with $M \beta C D$ were co-incubated with oocytes in droplets of $\mathrm{MW}+++\mathrm{pH}$ 7.25. To directly compare binding at equivalent $\mathrm{pH}$, an additional treatment using sperm incubated in $\mathrm{MW}+++$ at $\mathrm{pH} 7.9$ and co-incubated with oocytes in $\mathrm{MW}+++$ at $\mathrm{pH} 7.25$ was conducted.

To each oocyte-containing droplet, $10 \mu \mathrm{l}$ of the corresponding sperm suspension $\left(10 \times 10^{6} \mathrm{sperm} / \mathrm{ml}\right)$ were added, to yield a final concentration of $1 \times 10^{6} \mathrm{sperm} / \mathrm{ml}$. Once sperm had been added, the plates containing the droplets were placed in a $5 \% \mathrm{CO}_{2} / 95 \%$ air incubator at $39{ }^{\circ} \mathrm{C}$ and $100 \%$ humidity for $2 \mathrm{~h}$. After gamete co-incubation, the sperm-oocyte complexes were pipetted three times each in PBS supplemented with $0.2 \%$ of PVA, through a wide-bore glass pipette, to remove loosely attached spermatozoa. The sperm-oocyte complexes were then fixed in $4 \%$ formaldehyde in PBS supplemented with $0.2 \%$ PVA for $12 \mathrm{~h}$ at $4{ }^{\circ} \mathrm{C}$. Then, the complexes were washed with PBS supplemented with $0.2 \%$ PVA and stained with Hoechst 33342 at $5 \mu \mathrm{g} / \mathrm{ml}$ at $37{ }^{\circ} \mathrm{C}$ for $10 \mathrm{~min}$ in the dark. The complexes were mounted on slides using glycerol, covered with a cover slip, fixed using nail polish, and allowed to dry. The number of sperm bound to each oocyte was assessed using a CyScope Plus HP-Partec fluorescence microscope (Swedesboro, NY, USA) equipped with a $100 \times$ objective.

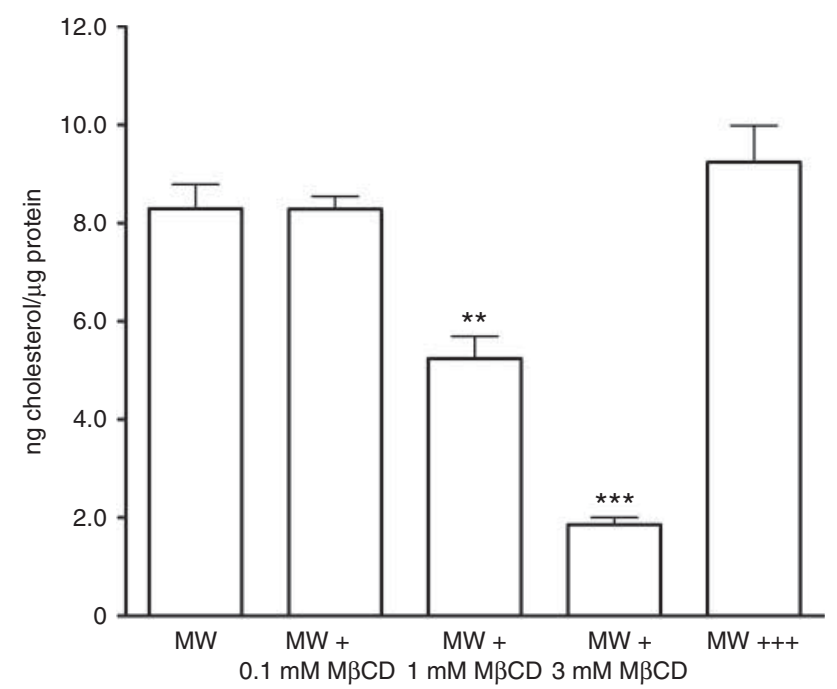

Figure 1 Effect of $M \beta C D$ on sperm cholesterol as assessed by fluorescent Amplex Red assay. Equine sperm were incubated for $4 \mathrm{~h}$ in $\mathrm{MW}+++$ or in MW supplemented with $0.1,1$, or $3 \mathrm{mM} \mathrm{M \beta CD}$. The amount of cholesterol in the sperm lysate was measured and normalized to its protein content (ng cholesterol/ $\mu \mathrm{g}$ protein). The experiment was carried out using five ejaculates from four different stallions $(n=4)$. Values bearing $* *(P<0.01)$ or $* * *(P<0.001)$ differ significantly from the MW treatment and the error bars represent the S.E.M. 


\section{Statistical analysis}

All data were first examined using the Shapiro-Wilk test to determine their distribution. All data resulting from the ROS production experiment, viability assays, PY immunofluorescence, and cholesterol determinations (with exceptions presented later), showed a normal distribution and differences between treatments were established using a one-way ANOVA. When differences were found, the Holm-Sidak method was used to perform multiple comparisons (treatment vs control group) for the cholesterol determinations, a Tukey post-hoc test was used to compare pairs of values in the ROS and a StudentNewman-Keuls post-hoc test was used for the PY experiments. For the heterologous binding experiments, in view of their nonGaussian distribution, an ANOVA on ranks test was used. As the group sizes were not equal in heterologous binding experiments, a Dunn's test post hoc was used; a StudentNewman-Keuls post-hoc test was used to compare pairs of values in the cholesterol determination. Statistical significance was set at $P<0.05$. Analyses were performed using SigmaPlot ver. 12.0 for Windows (Systat Software, Chicago, IL, USA).

\section{Results}

\section{Cholesterol content and distribution in equine sperm}

Results of the cholesterol quantification assay, evaluated on sperm incubated in basal MW (devoid of BSA, calcium and bicarbonate) treated with different concentrations of $M \beta C D$ to induce cholesterol efflux, and in sperm incubated in standard capacitating media (containing BSA, calcium, and bicarbonate; $\mathrm{MW}+++$ ), are presented in Fig. 1. Sperm cholesterol contents (ng cholesterol $/ \mu \mathrm{g}$ of protein; mean \pm S.E.M.) were 8.64 $\pm 0.51,8.69 \pm 0.46,5.24 \pm 0.45,2.08 \pm 0.26$, and $10.17 \pm 1.1$ for sperm incubated in MW supplemented with $M \beta C D$ at $0,0.1,1$ or $3 \mathrm{mM}$, or in $\mathrm{MW}+++$ respectively. Values for treatment groups containing 1 or $3 \mathrm{mM} M \beta C D$ were significantly lower than values for treatment groups containing 0 or $0.1 \mathrm{mM}$ M $\beta C D(P<0.01)$. No cholesterol efflux was detected in sperm exposed to BSA $(\mathrm{MW}+++)$ in comparison to the basal MW used as a control $(P>0.05)$.

These results show a lack of effect of BSA on cholesterol content in equine sperm; however, it is possible that the distribution of cholesterol within the plasma membrane may be affected, as reported previously in porcine sperm after the addition of BSA (Flesch et al. 2001). Thus, we assessed sperm incubated in the above treatments by filipin staining (Fig. 2). No differences were detected in the distribution pattern of filipin fluorescence for sperm incubated in MW $(0 \mathrm{mM}$ M $\beta C D), 0.1 \mathrm{mM} M \beta C D$, or $\mathrm{MW}+++$ treatments; however, a substantial decrease in overall filipin fluorescence was detected in 1 and $3 \mathrm{mM} \mathrm{M \beta CD}$
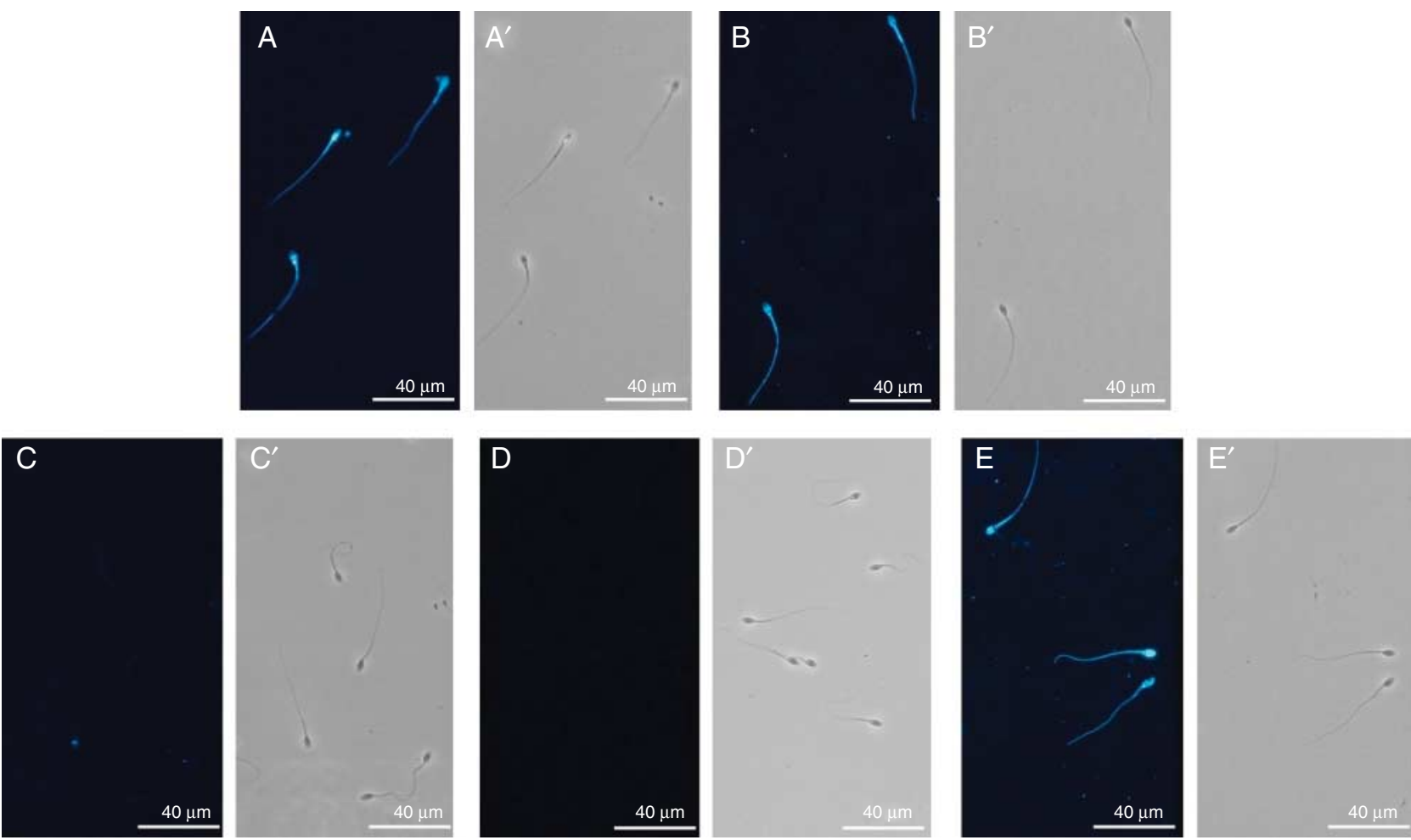

Figure 2 Distribution of equine sperm cholesterol assessed by filipin staining. Fluorescent microscopy (A, B, C, D, and E) and light microscopy ( $A^{\prime}, B^{\prime}$, $\mathrm{C}^{\prime}, \mathrm{D}^{\prime}$, and $\mathrm{E}^{\prime}$ ) of equine sperm stained using filipin and observed at $20 \times$ magnification. The letters represent the different media: (A) MW; (B) MW

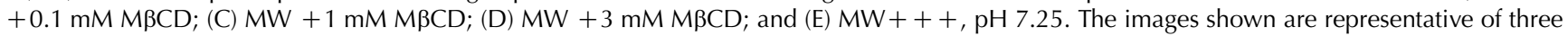
independent experiments (three stallions, one ejaculate per stallion; 100 sperm per sample). 


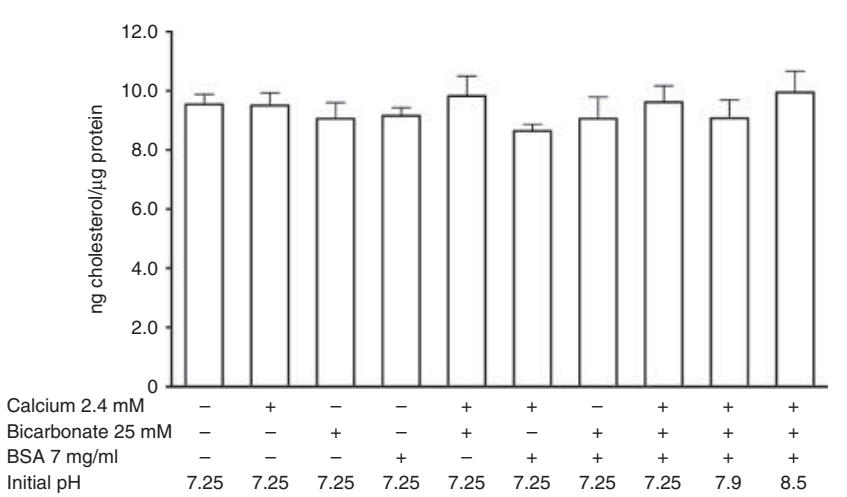

Figure 3 Effect of calcium, BSA, bicarbonate, and medium $\mathrm{pH}$ on sperm cholesterol content. Spermatozoa $\left(10 \times 10^{6} \mathrm{sperm} / \mathrm{ml}\right.$ in $\left.500 \mu \mathrm{l}\right)$ were incubated for $4 \mathrm{~h}$, lysed, and the amount of cholesterol measured and normalized to its protein content (ng cholesterol/ $\mu$ g protein). The experiment was carried out using four ejaculates from four different stallions $(n=4)$. No statistically significant differences were found among treatments $(P>0.05)$; the error bars represent the S.E.M.

treatments when compared with other treatment groups. In $1 \mathrm{mMM} \beta C D$, fluorescence was limited to remnants of the equatorial band, and, in $3 \mathrm{mM} \mathrm{M} \beta C D$, fluorescence was essentially eliminated. These findings support those of the cholesterol quantification assay (Fig. 1), in that treatment with $M \beta C D$ showed a dose-dependent reduction in the amount of equine sperm cholesterol, whereas BSA had no effect.

\section{Effect of calcium, BSA, bicarbonate, and medium $\mathrm{pH}$ on sperm cholesterol efflux}

To evaluate whether the cholesterol-acceptor ability of BSA in equine sperm was influenced by medium $\mathrm{pH}$, calcium, or bicarbonate, the cholesterol quantification assay was performed on sperm incubated in basal $\mathrm{MW}$, $\mathrm{MW}+\mathrm{Bic}, \mathrm{MW}+\mathrm{Ca}, \mathrm{MW}+\mathrm{BSA}$, or combinations of these additions at initial $\mathrm{pH} 7.25$, and in $\mathrm{MW}+++$ at initial pH 7.9 and $\mathrm{pH} 8.5$ (Fig. 3). No significant differences were found in cholesterol content among treatments $(P>0.05)$, indicating that none of the tested factors affected cholesterol efflux in equine sperm.

\section{Effect of albumin concentration and type on sperm cholesterol content}

To evaluate whether cholesterol efflux required different, possibly species-specific, serum albumin, or higher quantities of serum albumin, we assessed sperm cholesterol content after treatment with these factors. There was no reduction in the cholesterol content associated with incubation of equine sperm with BSA 7030 (used in the above studies), BSA 9418, hSA, eSA, or delipidated eSA (LD-eSA), at either 7 or $20 \mathrm{mg} / \mathrm{ml}$, whereas incubation with $3 \mathrm{mM} M \beta C D$ induced highly significant cholesterol depletion (Fig. 4). Incubation of sperm with non-delipidated eSA was associated with a significant increase in measured cholesterol.

When $5 \mu$ of media (without sperm) containing either 7 or $20 \mathrm{mg} / \mathrm{ml}$ of the different albumins were tested for cholesterol content, non-delipidated eSA was associated with a highly significant, dose-dependent increase in measured cholesterol levels, which was not present for delipidated eSA (LD-eSA), BSA 7030, or hSA (Fig. 5). Incorporation of cholesterol from the medium by sperm in this treatment may explain the increase in cholesterol content observed in sperm incubated in the presence of non-delipidated eSA. BSA 9418 showed a minor but significant increase in cholesterol between the 7 and $20 \mathrm{mg} / \mathrm{ml}$ solutions.

\section{Effect of medium components, $\mathrm{pH}$, and $M \beta C D$ addition on sperm ROS production}

ROS production has been shown to be associated with cholesterol oxidation and cholesterol efflux from the sperm plasmalemma (Boerke et al. 2013) and overall with sperm capacitation. As neither the three components, BSA, bicarbonate, and calcium, alone nor high $\mathrm{pH}$ induced a significant decrease in the cholesterol content of equine sperm, we tested whether these components alone or in combination were associated with increased sperm ROS production (Fig. 6). Incubation in MW + Bic resulted in the highest proportion of live sperm producing ROS $(31.5 \% \pm 4.9$; mean \pm s.E.M. $)$. Surprisingly, the addition of calcium and/or BSA resulted in a significant decrease in ROS production compared with incubation with $\mathrm{MW}+\mathrm{Bic}$ alone $(4.3 \% \pm 0.6$ and $5.1 \% \pm 1.3$ for the $\mathrm{MW}+\mathrm{Bic}+\mathrm{Ca}$ and $\mathrm{MW}+\mathrm{Bic}+\mathrm{BSA}$ treatments respectively; $P<0.05)$ or with incubation in MW alone $(16.9 \% \pm 4.3$ vs $6.4 \% \pm 1.0$ and $2.1 \% \pm 0.6$

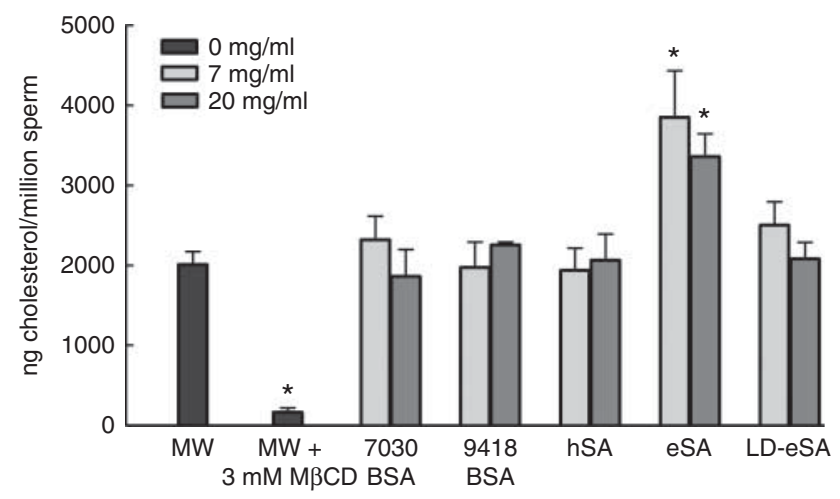

Figure 4 Effect of albumin concentration and type on sperm cholesterol content. Spermatozoa $\left(10 \times 10^{6} \mathrm{sperm} / \mathrm{ml}\right.$ in $\left.500 \mu \mathrm{l}\right)$ were incubated with different albumin sources and concentrations ( 7 or $20 \mathrm{mg} / \mathrm{ml}$ ) for $4 \mathrm{~h}$ in $\mathrm{MW}+\mathrm{Bic}+\mathrm{Ca}$; after the incubation the sperm were lysed, and the amount of cholesterol measured and normalized to the final sperm number (ng cholesterol/million sperm). The experiment was carried out using three ejaculates from three different stallions $(n=3)$. Values bearing * differ significantly $(P<0.05)$ from the MW treatment; the error bars represent the S.E.M. 


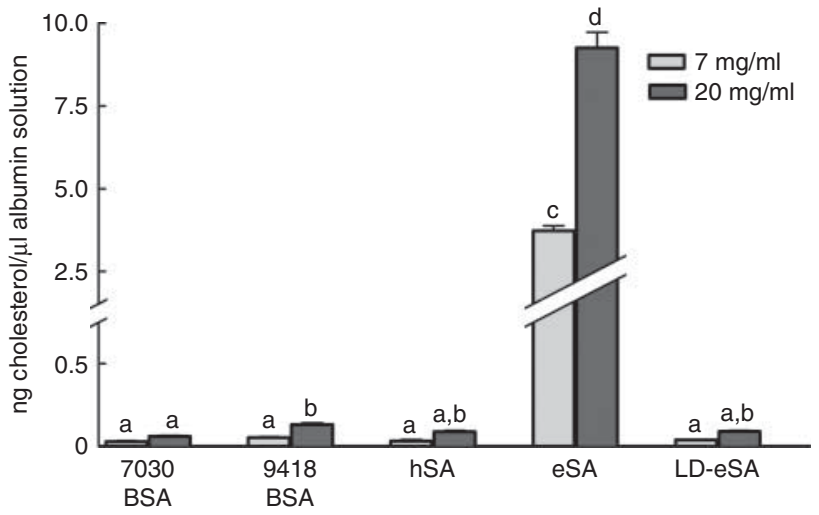

Figure 5 Cholesterol content of media containing different albumins in solution. Cholesterol concentrations (ng/per $\mu$ l albumin solution) of assay preparations made with $5 \mu \mathrm{MW}$ containing 7 or $20 \mathrm{mg} / \mathrm{ml}$ of the different tested albumins (hSA, human serum albumin; eSA, equine serum albumin; LD-eSA, delipidated equine serum albumin). Bars bearing different letters differ significantly $(P<0.05)$ and the error bars represent the S.E.M.

for $\mathrm{MW}+\mathrm{Ca}$ and $\mathrm{MW}+\mathrm{BSA}$ respectively), although in this case only the addition of BSA was statistically significant $(P<0.05)$. Neither $\mathrm{MW}+++$ at any of the $\mathrm{pH}$ values tested nor $M W+M \beta C D$ at any of the concentrations used resulted in a significant increase in ROS production.

\section{Protein tyrosine phosphorylation}

The protein tyrosine phosphorylation (PY) status of equine sperm was assessed by the increase in the percentage of sperm showing fluorescence, indicating phosphorylation of tyrosine residues, along the tail on immunocytochemistry (Fig. 7). PY was consistently increased when bicarbonate was added to the media either alone (MW+Bic; $43.8 \% \pm 10.1 \%)$ or in combination with BSA (MW + Bic + BSA; $42.3 \% \pm 6.4 \%)$ or calcium (MW + Bic $+\mathrm{Ca} ; 33.0 \% \pm 8.8 \%$ ) compared with MW alone (9.7\% $\pm 2.3 \%$; Fig. 7). When calcium, bicarbonate, and BSA were added $(\mathrm{MW}+++\mathrm{pH}$ 7.25), an increase in PY was observed but it was not significantly different from that for MW, due to the high variability existing between stallions in PY induction in these media, as reported previously (GonzalezFernandez et al. 2012). Induction of PY was pH dependent, as found previously (Gonzalez-Fernandez et al. 2012), with $\mathrm{MW}+++$ at $\mathrm{pH} 7.9$ and 8.5 showing the greatest prevalence of $\mathrm{PY}(50.3 \% \pm 7.3 \%$ and $59.7 \% \pm 4.2 \%$ respectively). Addition of $M \beta C D$ $(0.1-3 \mathrm{mM})$ to $\mathrm{MW}$ did not result in a significant increase in PY compared with MW (Fig. 7).

\section{Heterologous binding assay}

To evaluate the capability of equine sperm incubated under different conditions to bind to bovine ZP, sperm were incubated in $\mathrm{MW}, \mathrm{MW}+\mathrm{Bic}+\mathrm{Ca}$, and $\mathrm{MW}+++$ at $\mathrm{pH} 7.25$, or $\mathrm{MW}+++$ at $\mathrm{pH} 7.9$; sperm-ZP co-incubation was tested in those same media for the homologous treatments. In addition, sperm were also incubated in $\mathrm{MW}+++$, $\mathrm{pH} 7.25$, with 0.1 or $1 \mathrm{mM}$ $\mathrm{M} \beta \mathrm{CD}$, or in $\mathrm{MW}+++, \mathrm{pH} 7.9$, and were co-incubated with bovine oocytes in $\mathrm{MW}+++, \mathrm{pH} 7.25$. Sperm from each stallion tested (IP, XA and JC) responded similarly to the different media (Fig. 8), although the absolute number of sperm bound to bovine ZP differed significantly among stallions. For stallion IP, the experiment was repeated five times and a total of 252 oocytes per treatment were evaluated (34-39 per treatment). For stallion XA, the experiment was repeated five times and a total of 252 oocytes were evaluated (3238 per treatment). For these stallions, the number of sperm bound to the ZP was low enough to quantify. For stallion JC, the experiment was performed four times and a total of 180 oocytes were assessed (24-26 per treatment). For this stallion, the number of sperm bound to the ZP in some treatments was too high to quantify, and thus, representative photomicrographs are shown in Fig. 8 and statistical analyses were not performed. For all stallions, incubation in $\mathrm{MW}$ or in $\mathrm{MW}+\mathrm{Bic}+\mathrm{Ca}$ did not induce appreciable sperm binding to the ZP; however, addition of BSA $(\mathrm{MW}+++)$ induced a marked increase in the number of sperm bound to the ZP compared with that for MW or $\mathrm{MW}+\mathrm{Bic}+\mathrm{Ca}$ (significant for quantified stallions (IP and $X A ; P>0.05)$. In stallion $I P$, an additional significant increase in sperm-ZP binding was observed in sperm incubated in $\mathrm{MW}+++$ supplemented with $1 \mathrm{mM}$ M $\beta C D(P<0.01)$; however, this was not true for Stallion $X A$, and no difference could be appreciated between these treatments in stallion JC.

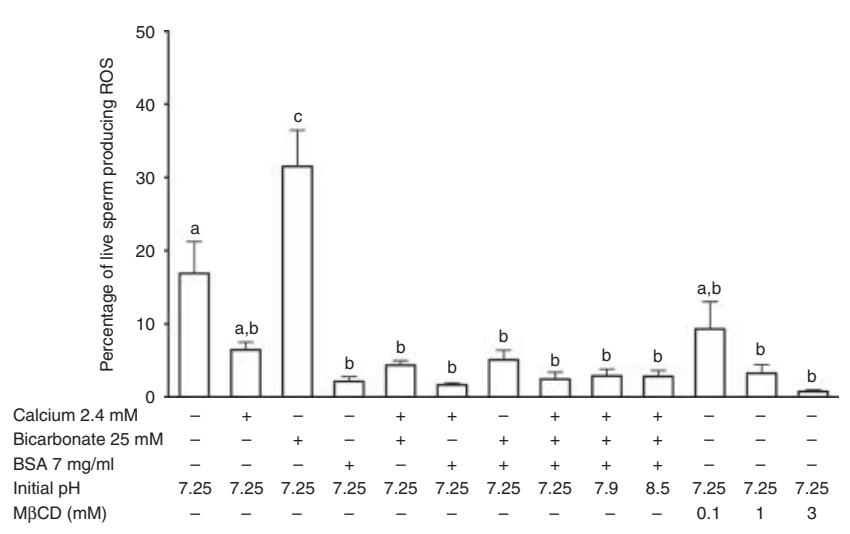

Figure 6 Effect of media components, $\mathrm{pH}$, and $M \beta C D$ addition on sperm ROS production. Sperm were incubated at a concentration of $10 \times 10^{6} \mathrm{million} / \mathrm{ml}$ at $37^{\circ} \mathrm{C}$ in air for $4 \mathrm{~h}$ in the designated media. One hundred $\mu \mathrm{l}$ were diluted in $900 \mu \mathrm{l}$ of PBS, incubated with $5 \mu \mathrm{M}$ of DCFDA for $30 \mathrm{~min}$ at $37^{\circ} \mathrm{C}$ in the dark, and $1 \mu \mathrm{M}$ of PI was added in the last $5 \mathrm{~min}$. ROS production in live cells was measured using a flow cytometer. Three ejaculates from three different stallions were used $(n=3)$; bars bearing different letters differ significantly $(P<0.05)$ and the error bars represent the S.E.M. 


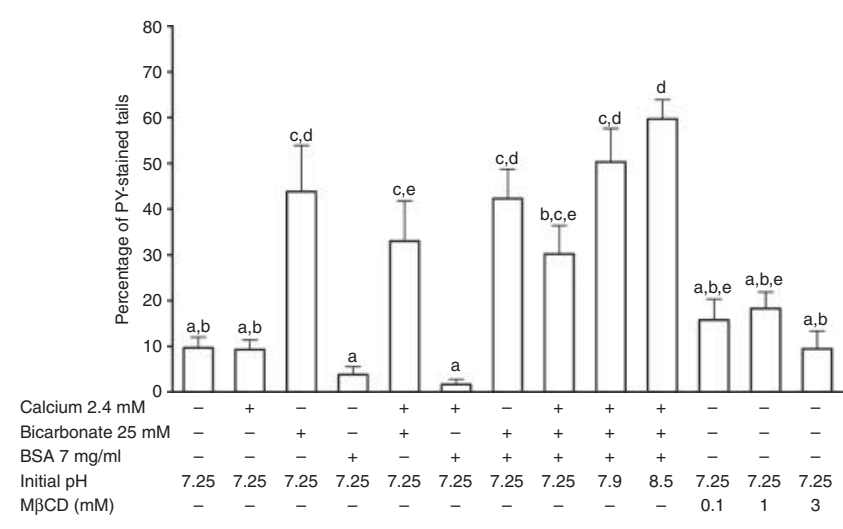

Figure 7 Percentage of sperm tails showing positive phosphotyrosine labeling. Sperm were incubated at a concentration of $10 \times 10^{6}$ million/ml in the given media at $37^{\circ} \mathrm{C}$ in air for $4 \mathrm{~h}$. Two ejaculates from three different stallions were used $(n=6)$. One hundred sperm per sample were evaluated using a fluorescence microscope $(100 \times)$ and the percentage of stained tails was calculated. Bars bearing different letters differ significantly $(P<0.05)$; the error bars represent the S.E.M.

\section{Discussion}

The results of this study demonstrate that, in equine sperm, exposure to standard capacitating conditions (medium containing BSA, bicarbonate, and calcium) results in neither ROS production nor cholesterol efflux, even under conditions (increased medium $\mathrm{pH}$ ) associated with increased PY (Figs 1, 2, 3, 4, 5, 6, and 7). This is in direct contrast to findings in murine (Visconti et al. 1999b), porcine (Flesch et al. 2001), and human sperm (Osheroff et al. 1999).

Flesch et al. (2001) reported that albumin-mediated cholesterol extraction from boar sperm was dependent upon bicarbonate; in combination, bicarbonate and BSA stimulated a marked decrease (up to 30\%) in the cholesterol content of porcine sperm, and presence of BSA, calcium, and bicarbonate induced a vivid change in cholesterol distribution, as detected by filipin staining. This finding is in agreement with that of Boerke et al. (2013), who reported that bicarbonate or other prooxidants induced ROS production, which, in turn, stimulated cholesterol oxidation and promoted cholesterol efflux in porcine and murine sperm. By contrast, we found no change in cholesterol distribution or content in equine sperm subjected to $4 \mathrm{~h}$ of incubation in the presence of bicarbonate, calcium, and BSA, alone or in combination, nor did we find a decrease in the cholesterol content associated with the treatment that significantly promoted ROS production $(\mathrm{MW}+\mathrm{Bic})$ (Figs 1, 2, 3, and 6).

The lack of decrease in membrane cholesterol content in equine sperm exposed to BSA could be attributed to an insufficient albumin concentration or the need of a different albumin source; it has previously been reported that different albumin preparations and source (bovine vs human) vary in their ability to support human sperm capacitation (Ravnik et al. 1990, 1993). However, we found no effect of different albumin sources (human, equine, or bovine) or concentrations $(0,7$ or $20 \mathrm{mg} / \mathrm{ml}$; Figs 4 and 5) on the cholesterol content of equine sperm. In fact, the non-delipidated eSA increased the sperm cholesterol content. Our results are consistent with those of Go \& Wolf (1985), which demonstrated that, in mice, cholesterol-loaded BSA increased sperm cholesterol content, inhibiting capacitation and decreasing fertilization rates in vitro. The results of our experiments indicate that non-delipidated albumins should be avoided when working with equine sperm to prevent cholesterol transfer.

The highest levels of ROS production were found in sperm incubated in MW + Bic or MW (Fig. 6). Surprisingly, BSA and calcium, alone or in combination, significantly inhibited ROS production in both MW+ Bic and MW media (Fig. 6). These findings are in contrast to those in boar (Matas et al. 2010) and human sperm (O'Flaherty et al. 2005), in which capacitating conditions (media containing bicarbonate, BSA, and calcium) increased ROS production and PY. To the best of our knowledge, inhibitory effects of calcium and BSA on ROS production during capacitation have not been reported previously in sperm of any species.

As we have previously reported (Gonzalez-Fernandez et al. 2012), when bicarbonate was added to the medium under the conditions of this study $\left(10 \times 10^{6} \mathrm{sperm} / \mathrm{ml}\right.$ in $500 \mu \mathrm{l}$ and incubation in air), an increase in PY was observed (Fig. 7). We have previously found that this increase in PY was attributable to the increase in $\mathrm{pH}$ associated with incubation of bicarbonate-containing medium in air (e.g., at initial pH 7.25, the final pH of bicarbonate-containing medium after $4 \mathrm{~h}$ of incubation in air is 7.7-8.0 (Gonzalez-Fernandez et al. 2012)). Correspondingly, a significant increase in the percentage of PY-stained sperm was observed in this study in $\mathrm{MW}+++$ when the initial medium $\mathrm{pH}$ was raised (Fig. 7). However, $\mathrm{MW}+++$ at high $\mathrm{pH}$ was associated neither with cholesterol depletion nor with enhanced ROS production (Figs 3 and 6). This finding is notable, as Visconti et al. (1999b) found that, under standard conditions, PY in mouse sperm was dependent upon cholesterol efflux. Thus, the increase in PY found in equine sperm in response to high $\mathrm{pH}$ does not seem to reflect other ongoing capacitation-related changes. These results show that relationships among ROS production, PY, and cholesterol efflux during capacitation in equine sperm may be regulated differently than are those of other domestic species, in which these events are intimately related (Aitken \& Nixon 2013). Supporting this theory, while standard capacitating medium under increasing $\mathrm{pH}$ induces equine sperm $\mathrm{PY}$ (McPartlin et al. 2008, Gonzalez-Fernandez et al. 2012), this was not associated with effective IVF (McPartlin et al. 2009). Overall, this suggests that PY induction is not a 

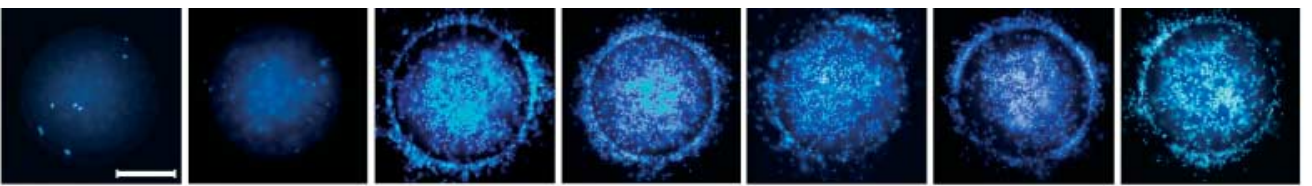

Stallion JC
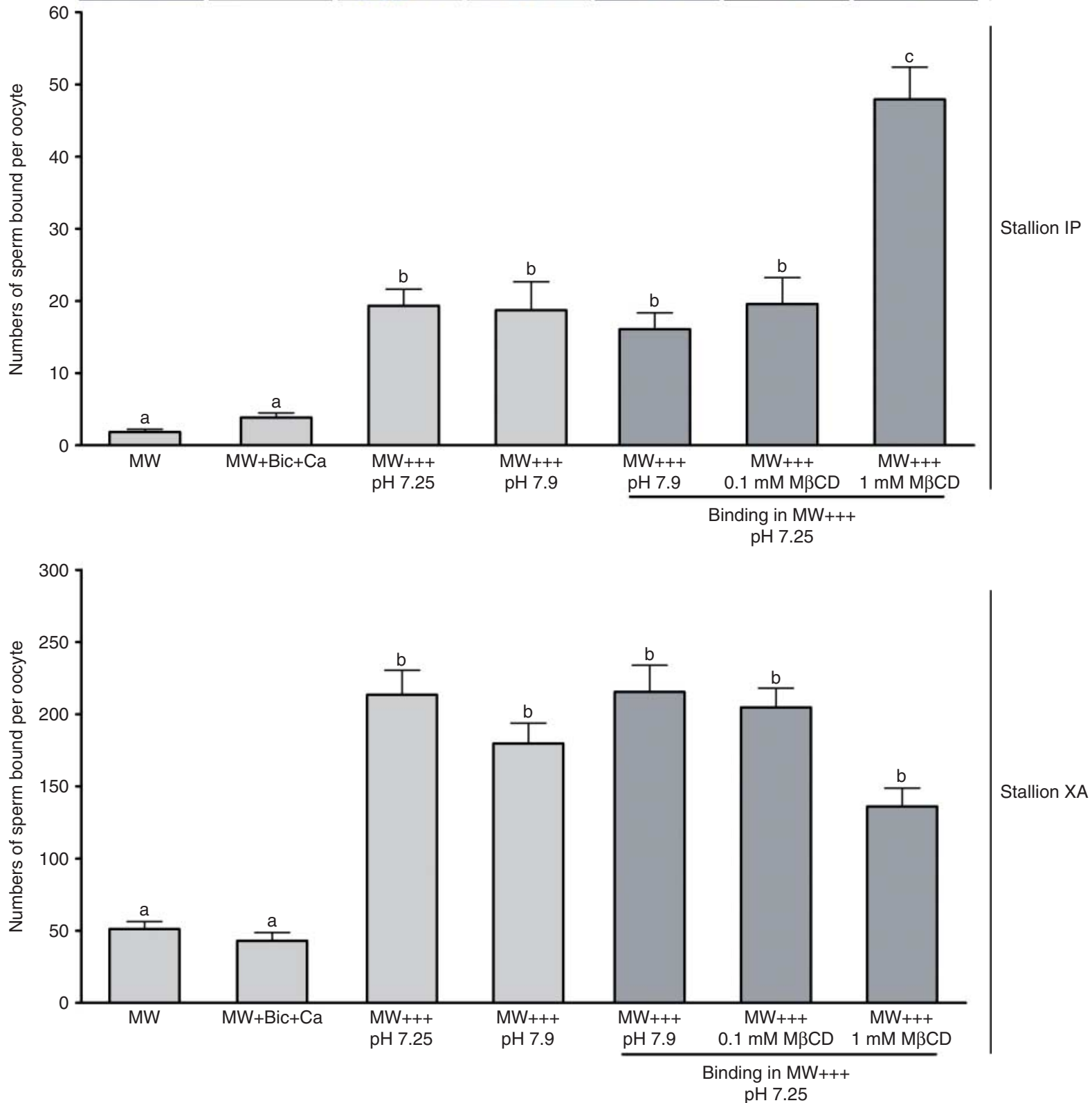

Figure 8 Number of equine sperm bound to bovine ZP. Equine sperm $\left(1 \times 10^{6} \mathrm{sperm} / \mathrm{ml}\right)$ and bovine oocytes (five to seven per droplet) were co-incubated for $2 \mathrm{~h}$ after sperm capacitation. The values given represent the number of equine sperm bound to bovine ZP for stallion IPand XA; bars bearing different superscripts differ significantly $(P<0.05)$; the error bars represent the S.E.M. The microphotographs are representative of the number of sperm bound to bovine ZP for stallion JC. A minimum of 24 oocytes were evaluated per treatment for each stallion. Sperm-oocyte complexes were stained using Hoechst 33342 and observed at $20 \times$ magnification; the bar represents a scale of $100 \mu \mathrm{m}$.

reliable indicator of capacitation (acquisition of fertilization ability) in equine sperm.

The only treatment that consistently induced a significant decrease in sperm cholesterol content was $\mathrm{MW}$ with $\mathrm{M} \beta C D$ at 1 and $3 \mathrm{mM}$ (Figs 1 and 2). Incubation with $M \beta C D$ has been shown to extract cholesterol from sperm plasmalemma of different mammalian species (Visconti et al. 1999c, Bromfield et al. 2014). Consistent with our findings, Boerke et al. (2013) found in porcine sperm that cholesterol efflux mediated by MBCD is ROS independent, unlike BSAmediated cholesterol extraction, which requires the 
formation of oxysterols. In addition, $M \beta C D$ extracts cholesterol from the entire sperm membrane, while BSA does not affect cholesterol content of the detergentresistant membrane fraction (Boerke et al. 2008). $\mathrm{M} \beta C D$-induced cholesterol loss in porcine sperm was associated with an increase in PY (Boerke et al. 2013). By contrast, we found that, in equine sperm, $M \beta C D$ induced cholesterol efflux was not related to a significant increase in PY compared with MW alone (Fig. 7).

While our results show that BSA appears to be associated neither with cholesterol efflux nor with PY induction in equine sperm, it is possible that BSA has other, non-cholesterol-related effects that could potentiate capacitation in equine sperm, as BSA has been shown to increase sperm intracellular alkalinization (Zeng et al. 1996, Huang et al. 2005) and to trigger calcium influx through the CatSper ion channel in mouse sperm (Xia \& Ren 2009). Incubation with BSA did increase binding of equine sperm to bovine ZP in our heterologous binding assay. The increase in ZP binding associated with the presence of BSA does not appear to be related to extraction of cholesterol from the sperm (Figs 1, 2, 3, and 4) or to a rise in ROS. Albumin causes equine sperm to become 'sticky', as presence of BSA is associated with sperm agglutination (Bromfield et al. 2014), and thus, the increase in zona binding may be non-specific. However, equine sperm-bovine ZP binding can be functional, as acrosome reaction and penetration through bovine ZP have been shown to take place (Sinowatz et al. 2003). In our experiments, we observed an individual variability among stallions in the number of sperm attached to bovine $\mathrm{ZP}$, as described previously (Balao da Silva et al. 2013). Additionally, incubation with $M \beta C D$ did not affect sperm binding in two stallions, but in one stallion (IP), incubation with $1 \mathrm{mM} \mathrm{M} \beta C D$ in $M W+++$ increased sperm binding over $\mathrm{MW}+++$ alone. Only 0.1 and $1 \mathrm{mM} \mathrm{M \beta CD}$ were tested in our experiments due to a marked loss of motility of equine sperm when exposed to $3 \mathrm{mM} \mathrm{M} \beta C D$; this effect was not related to a significant loss of sperm viability (membrane integrity), as determined by PI staining (Supplementary Figure 1, see section on supplementary data given at the end of this article). Interestingly, stallion IP had the lowest baseline sperm binding of the three stallions evaluated; it is possible that, perhaps due to different membrane compositions among stallions (Garcia et al. 2011), a too rigid membrane failed to express areas to which BSA could bind to cause 'stickiness'; the effect of M $B C D$ in this stallion highlights the stallion-to-stallion variability found in other capacitation-related events such as PY (Gonzalez-Fernandez et al. 2012). Bromfield et al. (2014) reported that MBCD improved binding of equine sperm to bovine ZP; however, individual variability was not appreciated in that study, as the authors pooled ejaculates from three stallions.
In conclusion, our results show that neither serum albumin nor bicarbonate, either alone or in combination, is associated with cholesterol efflux from equine sperm. Bicarbonate alone induced a rise in ROS production and an increase in PY. Addition of calcium or BSA dramatically blunted ROS production, but not PY. Increasing $\mathrm{pH}$ induced an increase in PY that was not related to cholesterol efflux, increased ROS production, or improved sperm-ZP binding. To the best of our knowledge, this is the first report revealing that incubation with BSA is not associated with cholesterol efflux from equine sperm and that ROS production does not occur under standard capacitating conditions (presence of bicarbonate, calcium, and BSA). The addition of BSA increased the percentage of ZP binding in all stallions tested, independent of PY induction, ROS production, or cholesterol efflux. Thus, this study demonstrates apparent species-specific differences in conditions for sperm membrane cholesterol efflux and in the relationship between ROS and cholesterol efflux, and capacitation-related events for the first time. Our findings corroborate previous reports that equine sperm do not undergo functional capacitation under standard capacitating conditions, and bring into question the validity of PY as a parameter of functional capacitation in equine sperm. More work is required to understand the molecular changes undergone by equine sperm in preparation for fertilization, and to increase our understanding of the roles of the different medium components that may support a repeatable equine IVF protocol.

\section{Supplementary data}

This is linked to the online version of the paper at http://dx.doi. org/10.1530/REP-14-0457.

\section{Declaration of interest}

The authors declare that there is no conflict of interest that could be perceived as prejudicing the impartiality of the research reported.

\section{Funding}

This work was supported by the Link Equine Research Endowment Fund, Texas A\&M University; the Legends Premier Stallion Auction Fund, Texas A\&M University; the College of Veterinary Medicine Postdoctoral Trainee Research Grant program, Texas A\&M University (B Macías-García); and European funds FEDER through the COMPETE program and by national funding of the Fundação para a Ciência e a Tecnologia, project: PTDC/CVT/108456/2008. B MacíasGarcía was funded by a postdoctoral grant of the Fundação para a Ciência e a Tecnologia, reference: SFRH/ BPD/84354/2012 (Portugal). L González-Fernández was supported by a postdoctoral grant of the Fundação para a 
Ciência e a Tecnologia, reference: SFRH/BPD/85532/2012 (Portugal).

\section{Acknowledgements}

This paper is dedicated to Daniela González Macías. The authors wish to thank the generous collaboration of the laboratory of the Section of Theriogenology, Texas A\&M University College of Veterinary Medicine, and particularly Mrs Sheila Teague for her help in collection of semen from stallions. They thank Dr Graça Lopes for her valuable help. They also thank Ms Sheila Spacek and Mr Paulo Ferreira for their technical assistance. The collaboration of Carnes Landeiro abattoir for bovine ovary supply is highly appreciated.

\section{References}

Aitken RJ \& Nixon B 2013 Sperm capacitation: a distant landscape glimpsed but unexplored. Molecular Human Reproduction 19 785-793. (doi:10.1093/molehr/gat067)

Austin CR 1951 Observations on the penetration of the sperm in the mammalian egg. Australian Journal of Scientific Research. Ser. B: Biological Sciences 4 581-596.

Balao da Silva CM, Spinaci M, Bucci D, Giaretta E, Pena FJ, Mari G \& Galeati G 2013 Effect of sex sorting on stallion spermatozoa: heterologous oocyte binding, tyrosine phosphorylation and acrosome reaction assay. Animal Reproduction Science 141 68-74. (doi:10.1016/j. anireprosci.2013.07.008)

Baumber J, Sabeur K, Vo A \& Ball BA 2003 Reactive oxygen species promote tyrosine phosphorylation and capacitation in equine spermatozoa. Theriogenology 60 1239-1247. (doi:10.1016/S0093-691X(03)00144-4)

Boerke A, Tsai PS, Garcia-Gil N, Brewis IA \& Gadella BM 2008 Capacitation-dependent reorganization of microdomains in the apical sperm head plasma membrane: functional relationship with zona binding and the zona-induced acrosome reaction. Theriogenology $\mathbf{7 0}$ 1188-1196. (doi:10.1016/j.theriogenology.2008.06.021)

Boerke A, Brouwers JF, Olkkonen VM, van de Lest $\mathrm{CH}$, Sostaric $\mathrm{E}_{\text {, }}$ Schoevers EJ, Helms JB \& Gadella BM 2013 Involvement of bicarbonateinduced radical signaling in oxysterol formation and sterol depletion of capacitating mammalian sperm during in vitro fertilization. Biology of Reproduction 88 21. (doi:10.1095/biolreprod.112.101253)

Bromfield EG, Aitken RJ, Gibb Z, Lambourne SR \& Nixon B 2014 Capacitation in the presence of methyl- $\beta$-cyclodextrin results in enhanced zona pellucida-binding ability of stallion spermatozoa. Reproduction 147 153-166. (doi:10.1530/REP-13-0393)

Brouwers JF, Boerke A, Silva PF, Garcia-Gil N, van Gestel RA, Helms JB, van de Lest CH \& Gadella BM 2011 Mass spectrometric detection of cholesterol oxidation in bovine sperm. Biology of Reproduction $\mathbf{8 5}$ 128-136.

Chang MC 1951 Fertilizing capacity of spermatozoa deposited into the fallopian tubes. Nature 168 697-698. (doi:10.1038/168697b0)

Choi YH \& Toyoda Y 1998 Cyclodextrin removes cholesterol from mouse sperm and induces capacitation in a protein-free medium. Biology of Reproduction 59 1328-1333. (doi:10.1095/biolreprod59.6.1328)

Choi YH, Landim-Alvarenga FC, Seidel GE Jr \& Squires EL 2003 Effect of capacitation of stallion sperm with polyvinylalcohol or bovine serum albumin on penetration of bovine zona-free or partially zona-removed equine oocytes. Journal of Animal Science 81 2080-2087.

Coutinho da Silva MA, Seidel GE Jr, Squires EL, Graham JK \& Carnevale EM 2012 Effects of components of semen extenders on the binding of stallion spermatozoa to bovine or equine zonae pellucidae. Reproduction 143 577-585. (doi:10.1530/REP-11-0099)

Dona G, Fiore C, Andrisani A, Ambrosini G, Brunati A, Ragazzi E, Armanini D, Bordin L \& Clari G 2011 Evaluation of correct endogenous reactive oxygen species content for human sperm capacitation and involvement of the NADPH oxidase system. Human Reproduction 26 3264-3273. (doi:10.1093/humrep/der321)
Flesch FM \& Gadella BM 2000 Dynamics of the mammalian sperm plasma membrane in the process of fertilization. Biochimica et Biophysica Acta 1469 197-235. (doi:10.1016/S0304-4157(00)00018-6)

Flesch FM, Brouwers JF, Nievelstein PF, Verkleij AJ, van Golde LM, Colenbrander B \& Gadella BM 2001 Bicarbonate stimulated phospholipid scrambling induces cholesterol redistribution and enables cholesterol depletion in the sperm plasma membrane. Journal of Cell Science 114 3543-3555.

Freeman SL \& England GC 2013 Storage and release of spermatozoa from the pre-uterine tube reservoir. PLOS ONE 8 e57006. (doi:10.1371/ journal.pone.0057006)

Gadella BM \& Van Gestel RA 2004 Bicarbonate and its role in mammalian sperm function. Animal Reproduction Science 82-83 307-319. (doi:10.1002/j.1939-4640.1990.tb03230.x)

Garcia BM, Fernandez LG, Ferrusola CO, Salazar-Sandoval C, Rodriguez AM, Martinez HR, Tapia JA, Morcuende D \& Pena FJ 2011 Membrane lipids of the stallion spermatozoon in relation to sperm quality and susceptibility to lipid peroxidation. Reproduction in Domestic Animals 46 141-148. (doi:10.1111/j.1439-0531.2010. 01609.x)

Go KJ \& Wolf DP 1985 Albumin-mediated changes in sperm sterol content during capacitation. Biology of Reproduction 32 145-153. (doi:10.1095/ biolreprod32.1.145)

Gonzalez-Fernandez L, Macias-Garcia B, Velez IC, Varner DD \& Hinrichs K 2012 Calcium-calmodulin and $\mathrm{pH}$ regulate protein tyrosine phosphorylation in stallion sperm. Reproduction 144 411-422. (doi:10.1530/REP-12-0067)

Gonzalez-Fernandez L, Macias-Garcia B, Loux SC, Varner DD \& Hinrichs K 2013 Focal adhesion kinases and calcium/calmodulindependent protein kinases regulate protein tyrosine phosphorylation in stallion sperm. Biology of Reproduction 88 138. (doi:10.1095/biolreprod.112.107078)

Griveau JF, Renard P \& Le Lannou D 1994 An in vitro promoting role for hydrogen peroxide in human sperm capacitation. International Journal of Andrology 17 300-307. (doi:10.1111/j.1365-2605.1994.tb01260.x)

Huang YH, Kuo SP, Lin MH, Shih CM, Chu ST, Wei CC, Wu TJ \& Chen YH 2005 Signals of seminal vesicle autoantigen suppresses bovine serum albumin-induced capacitation in mouse sperm. Biochemical and Biophysical Research Communications 338 1564-1571. (doi:10.1016/ j.bbrc.2005.10.120)

Kota V, Rai P, Weitzel JM, Middendorff R, Bhande SS \& Shivaji S 2010 Role of glycerol-3-phosphate dehydrogenase 2 in mouse sperm capacitation. Molecular Reproduction and Development 77 773-783. (doi:10.1002/ $\operatorname{mrd} .21218$ )

de Lamirande E, Lamothe G \& Villemure M 2009 Control of superoxide and nitric oxide formation during human sperm capacitation. Free Radical Biology \& Medicine 46 1420-1427. (doi:10.1016/j.freeradbiomed. 2009.02.022)

Matas C, Sansegundo M, Ruiz S, Garcia-Vazquez FA, Gadea J, Romar R \& Coy P 2010 Sperm treatment affects capacitation parameters and penetration ability of ejaculated and epididymal boar spermatozoa. Theriogenology 74 1327-1340. (doi:10.1016/j.theriogenology.2010. 06.002)

McPartlin LA, Littell J, Mark E, Nelson JL, Travis AJ \& Bedford-Guaus SJ 2008 A defined medium supports changes consistent with capacitation in stallion sperm, as evidenced by increases in protein tyrosine phosphorylation and high rates of acrosomal exocytosis. Theriogenology 69 639-650. (doi:10.1016/j.theriogenology.2007.11.016)

McPartlin LA, Suarez SS, Czaya CA, Hinrichs K \& Bedford-Guaus SJ 2009 Hyperactivation of stallion sperm is required for successful in vitro fertilization of equine oocytes. Biology of Reproduction 81 199-206. (doi:10.1095/biolreprod.108.074880)

Minervini F, Lacalandra GM, Filannino A, Garbetta A, Nicassio M, Dell'aquila ME \& Visconti A 2010 Toxic effects induced by mycotoxin fumonisin B1 on equine spermatozoa: assessment of viability, sperm chromatin structure stability, ROS production and motility. Toxicology In Vitro 24 2072-2078. (doi:10.1016/j.tiv.2010.05.024)

Morales CR, Marat AL, Ni X, Yu Y, Oko R, Smith BT \& Argraves WS 2008 ATP-binding cassette transporters ABCA1, ABCA7, and ABCG1 in mouse spermatozoa. Biochemical and Biophysical Research Communications 376 472-477. (doi:10.1016/j.bbrc.2008.09.009) 
Morales CR, Ni X, Smith CE, Inagaki N \& Hermo L 2012 ABCA17 mediates sterol efflux from mouse spermatozoa plasma membranes. Histology and Histopathology 27 317-328.

Nicholson AM \& Ferreira A 2009 Increased membrane cholesterol might render mature hippocampal neurons more susceptible to $\beta$-amyloidinduced calpain activation and tau toxicity. Journal of Neuroscience 29 4640-4651. (doi:10.1523/JNEUROSCI.0862-09.2009)

O'Flaherty C, de Lamirande E \& Gagnon C 2005 Reactive oxygen species and protein kinases modulate the level of phospho-MEK-like proteins during human sperm capacitation. Biology of Reproduction 73 94-105. (doi:10.1095/biolreprod.104.038794)

O'Flaherty C, de Lamirande E \& Gagnon C 2006 Positive role of reactive oxygen species in mammalian sperm capacitation: triggering and modulation of phosphorylation events. Free Radical Biology \& Medicine 41 528-540. (doi:10.1016/j.freeradbiomed.2006.04.027)

Ohtani Y, Irie T, Uekama K, Fukunaga K \& Pitha J 1989 Differential effects of $\alpha$-, $\beta$ - and $\gamma$-cyclodextrins on human erythrocytes. European Journal of Biochemistry 186 17-22. (doi:10.1111/j.1432-1033.1989.tb15171.x)

Osheroff JE, Visconti PE, Valenzuela JP, Travis AJ, Alvarez J \& Kopf GS 1999 Regulation of human sperm capacitation by a cholesterol effluxstimulated signal transduction pathway leading to protein kinase A-mediated up-regulation of protein tyrosine phosphorylation. Molecular Human Reproduction 5 1017-1026. (doi:10.1093/molehr/ 5.11.1017)

Palme N, Becher AC, Merkl M, Glosmann M, Aurich C \& Schafer-Somi S 2014 Immunolocalization of the cholesterol transporters ABCA1 and ABCG1 in canine reproductive tract tissues and spermatozoa. Reproduction in Domestic Animals 49 441-447. (doi:10.1111/rda.12294)

Pommer AC, Rutllant J \& Meyers SA 2003 Phosphorylation of protein tyrosine residues in fresh and cryopreserved stallion spermatozoa under capacitating conditions. Biology of Reproduction 68 1208-1214. (doi:10.1095/biolreprod.102.011106)

Ravnik SE, Zarutskie PW \& Muller CH 1990 Lipid transfer activity in human follicular fluid: relation to human sperm capacitation. Journal of Andrology 11 216-226. (doi:10.1002/j.1939-4640.1990.tb03230.x)

Ravnik SE, Albers JJ \& Muller CH 1993 A novel view of albumin-supported sperm capacitation: role of lipid transfer protein-I. Fertility and Sterility 59 629-638.

Rodriguez PC, Valdez LB, Zaobornyj T, Boveris A \& Beconi MT 2011 Nitric oxide and superoxide anion production during heparin-induced capacitation in cryopreserved bovine spermatozoa. Reproduction in Domestic Animals 46 74-81. (doi:10.1111/j.1439-0531.2010.01583.x)

Roy SC \& Atreja SK 2008 Effect of reactive oxygen species on capacitation and associated protein tyrosine phosphorylation in buffalo (Bubalus bubalis) spermatozoa. Animal Reproduction Science 107 68-84. (doi:10.1016/j.anireprosci.2007.06.024)

Shadan S, James PS, Howes EA \& Jones R 2004 Cholesterol efflux alters lipid raft stability and distribution during capacitation of boar spermatozoa. Biology of Reproduction 71 253-265. (doi:10.1095/biolreprod.103.026435)

Sinowatz F, Wessa E, Neumuller C \& Palma G 2003 On the species specificity of sperm binding and sperm penetration of the zona pellucida. Reproduction in Domestic Animals 38 141-146. (doi:10.1046/j.14390531.2003.00401.x)

Thomas AD, Meyers SA \& Ball BA 2006 Capacitation-like changes in equine spermatozoa following cryopreservation. Theriogenology 65 1531-1550. (doi:10.1016/j.theriogenology.2005.08.022)
Tulsiani DR \& Abou-Haila A 2011 Molecular events that regulate mammalian fertilization. Minerva Ginecologica 63 103-118.

Visconti PE, Moore GD, Bailey JL, Leclerc P, Connors SA, Pan D, OldsClarke P \& Kopf GS 1995 Capacitation of mouse spermatozoa. II. Protein tyrosine phosphorylation and capacitation are regulated by a cAMPdependent pathway. Development 121 1139-1150.

Visconti PE, Galantino-Homer H, Moore GD, Bailey JL, Ning X, Fornes M \& Kopf GS 1998 The molecular basis of sperm capacitation. Journal of Andrology 19 242-248. (doi:10.1002/j.1939-4640.1998.tb01994.x)

Visconti PE, Stewart-Savage J, Blasco A, Battaglia L, Miranda P, Kopf GS \& Tezon JG 1999a Roles of bicarbonate, CAMP, and protein tyrosine phosphorylation on capacitation and the spontaneous acrosome reaction of hamster sperm. Biology of Reproduction 61 76-84. (doi:10.1095/ biolreprod61.1.76)

Visconti PE, Ning X, Fornes MW, Alvarez JG, Stein P, Connors SA \& Kopf GS $1999 b$ Cholesterol efflux-mediated signal transduction in mammalian sperm: cholesterol release signals an increase in protein tyrosine phosphorylation during mouse sperm capacitation. Developmental Biology 214 429-443. (doi:10.1006/dbio.1999.9428)

Visconti PE, Galantino-Homer H, Ning X, Moore GD, Valenzuela JP, Jorgez CJ, Alvarez JG \& Kopf GS 1999c Cholesterol efflux-mediated signal transduction in mammalian sperm. $\beta$-cyclodextrins initiate transmembrane signaling leading to an increase in protein tyrosine phosphorylation and capacitation. Journal of Biological Chemistry 274 3235-3242. (doi:10.1074/jbc.274.5.3235)

Visconti PE, Krapf D, de la Vega-Beltran JL, Acevedo JJ \& Darszon A 2011 Ion channels, phosphorylation and mammalian sperm capacitation. Asian Journal of Andrology 13 395-405. (doi:10.1038/aja.2010.69)

Wertheimer EV, Salicioni AM, Liu W, Trevino CL, Chavez J, HernandezGonzalez EO, Darszon A \& Visconti PE 2008 Chloride Is essential for capacitation and for the capacitation-associated increase in tyrosine phosphorylation. Journal of Biological Chemistry 283 35539-35550. (doi:10.1074/jbc.M804586200)

Wessel D \& Flugge UI 1984 A method for the quantitative recovery of protein in dilute solution in the presence of detergents and lipids. Analytical Biochemistry 138 141-143. (doi:10.1016/00032697(84)90782-6)

Xia J \& Ren D 2009 The BSA-induced $\mathrm{Ca}^{+}{ }^{+}$influx during sperm capacitation is CATSPER channel-dependent. Reproductive Biology and Endocrinology 7 119. (doi:10.1186/1477-7827-7-119)

Yanagimachi R 1994 Mammalian fertilization in The Physiology of Reproduction, E. Knobil and J.D. Neil, Eds., pp. 189-317, Raven Press, New York, NY, USA.

Zeng Y, Oberdorf JA \& Florman HM $1996 \mathrm{pH}$ regulation in mouse sperm: identification of $\mathrm{Na}(+)-, \mathrm{Cl}(-)-$, and $\mathrm{HCO} 3(-)$-dependent and arylaminobenzoate-dependent regulatory mechanisms and characterization of their roles in sperm capacitation. Developmental Biology 173 510-520. (doi:10.1006/dbio.1996.0044)

Received 23 February 2014

First decision 1 April 2014

Revised manuscript received 12 October 2014

Accepted 27 October 2014 